\title{
Bound tritium: Preparation, measurement
}

\author{
M. Fournier, N. Coreau and A. Maigret \\ IPSN/DPRE/SERNAT/LMRE, bâtiment 501, Bois des Rames, 91400 Orsay cedex, France
}

\begin{abstract}
The tritium activity in the ecosystem is measured on various matrices. The tritium bound to organic matter represents the tritium fixed by the operation of living objects. The sample should be prepared to preserve the tritium abundance with no isotopic fractionation. Transformation of the test sample should be conducted in order to obtain the highest possible combustion water yield, with no isotopic exchange. The test samples to be used should be sufficient to perform the measurements with the lowest possible detection threshold.
\end{abstract}

\section{INTRODUCTION}

Tritum is basically incorporated to the food chain via water [1]. The incorporation mechanisms involve isotopic fractionation. The various components generated by organisms are included in the structures or are stored or metabolised. Along the food chain, transformations may result in accumulation effects, trough isotopic fractionation or storage. Measurement of the tritium activity in the continental and sea ecosystem has been performed at LMRE since 1997 on various matrices (food products, ground mosses, fish, algae,), applying the methods used for environmental surveys [2,3]. Various terms are proposed to specify the compartment in which the tritium activity is measured:

"Free tritium", or tritium as water in the sample ("free water"),

"Exchangeable tritium", or tritium bound to an atom, which can undergo isotopic exchange with water or waler vapour under the stability conditions of the molecule or sample,

"Organically bound tritium", or tritium bound to an atom, which cannot undergo isotopic exchange with water or water vapour under the stability conditions of the molecule or sample,

"Bound tritium"', the whole of "exchangeable" and "organically bound" tritium, after extraction of the fee tritium.

For better reproducibility and to prevent possible atmospheric contamination, it is recommended ioperform a single combustion for each test sample.

\section{SAMPLE PREPARATION}

Due to easy tritium exchange as hydroxyl or proton, the sample should be prepared in order to preserve the tritium abundance with no isotopic fractionation. Dehydration may be performed either by heating at various temperatures, oven drying, or vacuum freeze-drying.

\subsection{Selecting the drying mode: oven drying or freeze-drying?}

Oven drying generates a tritium enrichment of the combustion water resulting from the bound fraction and tritium activity of this bound fraction expressed in dry weight of the sample. The durations required 
for this drying mode generate modifications in the organic matter, either via microbial action (oxidizing, fermenting) or via temperature effect (baking). The isotopic fractionation is all the more important as the temperature is high (table 1).

Table 1: Oven drying Vs freeze-drying

\begin{tabular}{|c|c|c|c|c|c|c|c|}
\hline Sample & Type & $\begin{array}{c}\text { Free } \\
\text { tritium } \\
\text { Bq. } .^{-1}\end{array}$ & $+/-1 \sigma$ & $\begin{array}{l}\text { Bound } \\
\text { tritium } \\
\text { Bq.1 }{ }^{-1}\end{array}$ & $+/-1 \sigma$ & 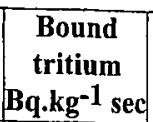 & $\pm 1 \sigma$ \\
\hline Grass & Grass & 2.57 & 0.12 & & & & \\
\hline Grass; freeze dried & Grass & & & $\overline{4}$ & 0.16 & 1.99 & $\overline{0.08}$ \\
\hline \multirow[t]{2}{*}{ Grass; oven dried: $60^{\circ} \mathrm{C}$} & Grass & & & 4.56 & 0.18 & 2.13 & 0.09 \\
\hline & Apples & $<1.21$ & DT & & & & \\
\hline Freeze dried & Apples & & & 1.98 & 0.12 & 0.97 & $0 . \overline{66}$ \\
\hline Oven dried: $105^{\circ} \mathrm{C}$ & Apples & & & 2.9 & 0.13 & 1.4 & 0.06 \\
\hline
\end{tabular}

When it is necessary to measure free tritium, freeze-drying should imperatively be selected. It is also recommended when measuring bound tritium. If exchangeable tritium is to be measured, this is the only technique to check the isotopic quantity and quality of the water used for exchange.

Full freeze drying is used to separate the "free water" without denaturing isotopic composition before the transformations required for measurement. This processing applies to all types of matrices (soils, sediments, milk, ground plants, water plants, fish, molluscs, food products,).

\subsection{Freeze-drying}

\subsubsection{Freeze drying system}

LMRE uses a locally procured system (HETO FD8). This programmable system consists of an evaporation chamber and a condenser separated by a shutoff valve (table 2 ).

Table 2: Features of the freeze-drying system.

\begin{tabular}{|l|l|}
\hline Chamber & $\begin{array}{l}\text { Independent cold unit. Number of trays: } 6 . \text { Each tray is cooled } / \text { heated: }-32^{\circ} \mathrm{C} \text { to }+70^{\circ} \mathrm{C} \text {, } \\
\text { within } \pm 0,5^{\circ} \mathrm{C} \text {, with a temperature check for the contents of each tray. Piranni sensor to } \\
\text { measure the vacuum within the chamber. Shutoff valve between chamber and condenser. }\end{array}$ \\
\hline Condenser & $\begin{array}{l}-85^{\circ} \mathrm{C}, 8 \mathrm{~kg} \text { of ice per } 24 \mathrm{hrs} \text {. Horizontal, stainless steel, smooth. With heater for fast de- } \\
\text { icing. Two-stage primary vacuum pump. Drain valve for fluid recovery. }\end{array}$ \\
\hline
\end{tabular}

\subsubsection{Preparation}

The system is dried with dry compressed air before installing the trays into the chamber. Trays are filled by weighing, in a dry room with regulated temperature $\left(20\right.$ to $\left.24^{\circ} \mathrm{C}\right)$, and quickly installed into the chamber. 
The freeze-drying phases include: pre-freezing, primary drying, and secondary drying. Each phase may be divided into steps, depending on the matrix under processing (table 3). The water/alcohol mixtures generated by freeze-drying are distilled to obtain the optimum water/alcohol separation. The alcohol fraction is added to the freeze-dried sample before combustion.

Table 3: Examples of freeze drying programs

\begin{tabular}{|l|l|l|l|l|l|}
\hline Matrix & \multicolumn{1}{|c|}{ Milk: 2 litres } & \multicolumn{1}{|c|}{ Honey: $1 \mathrm{~kg}$} & \multicolumn{1}{|c|}{ Grass: $0.7 \mathrm{~kg}$} & \multicolumn{1}{|c|}{ Apple: $3.2 \mathrm{~kg}$} & \multicolumn{1}{c|}{ Alga: $1.2 \mathrm{~kg}$} \\
\hline Freezing & $1:-25^{\circ} \mathrm{C}$ & $1:-32^{\circ} \mathrm{C}$ & $1:-32^{\circ} \mathrm{C}$ & $1:-32^{\circ} \mathrm{C}$ & $1:-32^{\circ} \mathrm{C}$ \\
& $2:-25^{\circ} \mathrm{C}, 3 \mathrm{hrs}$ & $2:-32^{\circ} \mathrm{C}, 20 \mathrm{hrs}$ & $2:-32^{\circ} \mathrm{C}, 4 \mathrm{hrs}$ & $2:-32^{\circ} \mathrm{C}, 5 \mathrm{hrs}$ & $2:-32^{\circ} \mathrm{C}, 5 \mathrm{hrs}$ \\
\hline Primary & $1:-10^{\circ} \mathrm{C}, 15 \mathrm{hrs}$ & $1:-20^{\circ} \mathrm{C}, 24 \mathrm{hrs}$ & $1:-10^{\circ} \mathrm{C}, 20 \mathrm{hrs}$ & $1:-10^{\circ} \mathrm{C}, 10 \mathrm{hrs}$ & $1:-20^{\circ} \mathrm{C}, 5 \mathrm{hrs}$ \\
drying & $2:-5^{\circ} \mathrm{C}, 7 \mathrm{hrs}$ & $2:-10^{\circ} \mathrm{C}, 20 \mathrm{hrs}$ & $2: 0^{\circ} \mathrm{C} ; 10 \mathrm{hrs}$ & $2: 0^{\circ} \mathrm{C}, 7 \mathrm{hrs}$ & $2:-10^{\circ} \mathrm{C}, 5 \mathrm{hrs}$ \\
P:0.5 hPa & & $3:-5^{\circ} \mathrm{C}, 10 \mathrm{hrs}$ & & & $3:-5^{\circ} \mathrm{C}, 5 \mathrm{hrs}$ \\
& & $4: 0^{\circ} \mathrm{C}, 20 \mathrm{hrs}$ & & & $4: 0^{\circ} \mathrm{C}, 5 \mathrm{hrs}$ \\
\hline Secondary & $1: 30^{\circ} \mathrm{C}, 9 \mathrm{hrs}$ & $1: 5^{\circ} \mathrm{C}, 5 \mathrm{hrs}$ & $1: 30^{\circ} \mathrm{C}, 10 \mathrm{hrs}$ & $1: 30^{\circ} \mathrm{C}, 10 \mathrm{hrs}$ & $1: 5{ }^{\circ} \mathrm{C}, 1 \mathrm{hrs}$ \\
dying & & $2: 10^{\circ} \mathrm{C}, 5 \mathrm{hrs}$ & & & $2: 10^{\circ} \mathrm{C}, 1 \mathrm{hrs}$ \\
P: final & & $3: 15^{\circ} \mathrm{C}, 5 \mathrm{hrs}$ & & & $3: 15^{\circ} \mathrm{C}, 1 \mathrm{hrs}$ \\
vacuum & & $4: 20^{\circ} \mathrm{C}, 5 \mathrm{hrs}$ & & & \\
& & $5: 20^{\circ} \mathrm{C}, 40 \mathrm{hrs}$ & & & \\
\hline
\end{tabular}

\subsection{End of freeze-drying criterion}

It is essential to check the sample dehydration. The selected criterion is the vacuum pressure: the value read should remain constant over 1 hour minimum and close to vacuum as obtained for the freeze drying system operating with the trays in the evaporation chamber at $30^{\circ} \mathrm{C}$ and the condenser at $-85^{\circ} \mathrm{C}$ without sample. Practically, this state results in an asymptotic graph of the pressure record.

\subsection{Sample preparation for the test sample}

After drying, the sample consistency is essential. The test sample for combustion ranges from 20 to $50 \mathrm{~g}$ (or $800 \mathrm{~g}$ ) depending on the matrices and available quantity of sample. The bound tritium distribution within the sample should be consistent, for the test sample to be representative. A too coarse crushing results in test samples that may be different in composition (table 4). A $100 \mu \mathrm{m}$ grain size is ideal. LMRE uses a grid-type crushing system with $80 \mu \mathrm{m}$ meshing.

Table 4: Heterogeneous sample

\begin{tabular}{c|c|c|c|c|}
\hline Type & $\begin{array}{c}\text { Combustion water } \\
\text { Bq. } .^{-1}\end{array}$ & $+/-1 \sigma$ & $\begin{array}{c}\text { Activity per kg of dry matter } \\
\text { Bq. } \mathrm{kg}^{-1} \mathrm{sec}\end{array}$ & $+/-1 \sigma$ \\
\hline Crab apple & 36.7 & 1.06 & 15.24 & 0.53 \\
\hline Crab apple & 39.75 & 1.18 & 15.1 & 0,55 \\
\hline
\end{tabular}

Both test samples for the same sample result in different values for the combustion water. These test samples are not identical with regard to tritium and composition. However, the expression of the dry 
matter activity of both test samples is identical. The tritium distribution is not consistent within the sample.

\subsection{Combustion}

\subsubsection{Combustion system}

The combustion oven access is fitted with a stove $\left(t=60^{\circ} \mathrm{C}\right)$ operating as an airlock, separated from the crystal combustion tube by a valve. The combustion tube goes through a moving oven with adjustable temperature $\left(t=\right.$ ambient to $\left.1000^{\circ} \mathrm{C}\right)$ and a fixed oven $\left(t=1000^{\circ} \mathrm{C}\right)$. In the fixed oven, the combustion tube is filled with a catalyst mixture (Deoxo $\mathrm{M}$ ) and crystal grains. The water vapour generated by combustion is condensed in a refrigerating system $\left(t=5^{\circ} \mathrm{C}\right.$ to $\left.75^{\circ} \mathrm{C}\right)$ fitted with a drum and a $U$-shaped tube, which are in turn cooled down (dry ice or liquid nitrogen). The combustion gases are exhausted through an S-shaped tube containing silica gel. The oxygen/argon mixture is adjustable. The test sample is loaded into one o: more crystal boats. The average duration of a combustion operation is equal to 10 hours, over 2 days: automatic warming up, weighing and boat loading, combustion, drying of the refrigerating system and recovery of the drum and U-shaped tube.

\subsubsection{End of combustion criterion}

The operator assesses the end of combustion by observing the absence of water vapour condensation in the coolants and by observing the contents of the combustion tube. Drying is performed under argon sweeping, with ovens at $1000^{\circ} \mathrm{C}$. The $\mathrm{pH}$ of the water generated by combustion should be acid, Otherwise, this water undergoes a combustion cycle.

\subsection{Distillation}

\subsubsection{Distillation system}

The distillation glassware was selected. It is kept in stove at $105^{\circ} \mathrm{C}$ before use. Parts are marked per item. The drum heaters are set to the minimum temperature to obtain distillation. The system includes: a $25 \mathrm{ml}$ drum with glass beads; a column; a three-way coupling; a coolant $\left(\mathrm{t}=5^{\circ} \mathrm{C}\right)$; an acceptance extension; a $15 \mathrm{ml}$ drum; a refrigerated "Dewar" vessel (dry ice or liquid nitrogen). The water samples are neutralized with calcium carbonate. The duration of a distillation is equal to 5 hours: assembly, weighing, distillation, drying, weighing.

\subsubsection{End of distillation criterion}

The operator assesses the end of distillation by observing the drum: it is essential to be close to dry distillation. Drying is performed with a hot air gun. The distillation yield should be more than $80 \%$. 


\section{MEASUREMENT}

\section{3,1 Measuring conditions}

As the water to be measured is distilled, the bottles forming a counting group are expected to have the same value for the parameter expressing quenching. Weighing is performed on two scales: one $1 / 10 \mathrm{mg}$ for the background ("blank") and samples, and the other $1 / 100 \mathrm{mg}$ for the reference. The counting bottles are low-diffusion, anti-static, polyethylene bottles (Packard ${ }^{\circledast} \mathrm{P} / \mathrm{N}$ 6000477). These bottles are stowed at $40^{\circ} \mathrm{C}$ and stored before use in a tight box containing silica gel. The scintillator quantity (Ultima Gold LLT), distributed by a pipette secured to the scintillator bottle (1L), and the pipetted test samples are weighed for checking. The optimum detection threshold is obtained for a mixture of $10 \mathrm{~g}$ of water in 10 $\mathrm{ml}$ of scintillator. Counts are performed on Packard 2770 TR-SL and LKB Quantulus ${ }^{\otimes}$ 12z0-002 counters. The instruments are cooled down to approximately $14^{\circ} \mathrm{C}$, in rooms regulated at $22^{\circ} \mathrm{C}$ and supplied in overpressure with filtered air at ambient temperature or heated to $20^{\circ} \mathrm{C}$. A counting group includes 8 bottles: a "blank", two samples, a reference (detection yield), and four samples. The counting duration is equal to 1000 minutes for each bottle, in 10 cycles of 100 minutes each. Under such conditions, the detection threshold varies between 1 and $1.5 \mathrm{~Bq} . \mathrm{L}^{-1}$, depending on the movement upon measurement. The uncertainty expressed within $1 \sigma$ incorporates weighing uncertainties for the reference and sample, the uncertainty on the reference activity and the counting uncertainties on the movement, the sample and the reference [4].

\subsection{Test sample}

In order to ensure an optimum $10 \mathrm{~g}$ quantity of water for the measurement, it is recommended to use test samples (tab.5) the combustion of which generates approximately $15 \mathrm{~g}$ of water.

Table 5: Examples of test samples for combustion

\begin{tabular}{|l|l|l|l|}
\hline \multicolumn{1}{|c|}{ Type } & \multicolumn{1}{|c|}{ Quantity (g) } & \multicolumn{1}{c|}{ Argon (\%) } \\
\hline Algae & 40 & 20 & 100 \\
\hline Sedimentation sludge & 50 to $200(\mathbf{5 0})$ & 25 to 100 & 75 to 0 \\
\hline Cereals & 30 to $40(\mathbf{3 5})$ & 40 & 60 \\
\hline Crustaceans & 30 to $50(\mathbf{5 0})$ & 25 & 80 \\
\hline Water & $12,5(\mathbf{1 5})$ & 100 & 0 \\
\hline Tree leaf & 24 to $40(\mathbf{3 0})$ & 20 & 80 \\
\hline Fruits & 30 to $40(\mathbf{3 8})$ & 20 & 80 \\
\hline Dry milk & 25 to $30(\mathbf{2 7})$ & 20 & 80 \\
\hline Vegetable & 30 to $60(\mathbf{4 0})$ & 20 & 80 \\
\hline iry leafs & 24 to $30(\mathbf{3 0})$ & 20 & 80 \\
\hline Mollusc & 30 to $45(\mathbf{3 5})$ & 30 & 70 \\
\hline Ground moss & 20 to $110(\mathbf{2 0})$ & 20 & 80 \\
\hline Water moss & 30 to $80(\mathbf{3 5})$ & 20 & 80 \\
\hline Fish & 30 to $50(\mathbf{3 0})$ & 30 & 70 \\
\hline Fat fish & 25 to $30(\mathbf{2 5})$ & 20 & 80 \\
\hline Meadow, pasture & 25 to $40(\mathbf{2 5})$ & 20 & 80 \\
\hline Salad & 30 to $40(\mathbf{3 5})$ & 20 & 80 \\
\hline Dark sediment & 50 to $500(\mathbf{1 5 0})$ & 30 to 100 & 70 to 0 \\
\hline Light sediment & 300 to $800(\mathbf{8 0 0})$ & 100 & 0 \\
\hline Soil & 50 to $500(\mathbf{3 0 0})$ & 30 to 100 & 70 to 0 \\
\hline Sugar & 30 & 40 & 60 \\
\hline The values & & \\
\hline
\end{tabular}

The values in parentheses are those most frequently used. 


\section{CONCLUSION}

The freeze dried product contains the "bound tritium", plus a fraction corresponding to the tritium contained in the exchangeable radicals, as $-\mathrm{OH},=\mathrm{N}-\mathrm{H},-\mathrm{S}-\mathrm{H}$. The systematic observation of "free tritium" and "bound tritium" values for the same type of vegetal sample does not evidence a systematic relationship between both forms, even in a specific context (La Hague)[5]. It should be noted that the value of the "free tritium" fraction, a priori balanced with the "exchangeable tritium" fraction, indicates the qualitative importance of the error made when considering the "bound tritium" value as being representative of the "organically bound tritium" while not exchanging the "exchangeable tritium". A low value of tritium abundance in the "free tritium" fraction, with regard to the "bound tritium" fraction, results in underestimating the value of tritium abundance in the "organically bound tritium" fraction. A high value of tritium abundance in the "free tritium" fraction results in overestimating the value of tritium abundance in the "organically bound tritium" fraction. These estimate errors (some \%) are all the more important, as the freeze-dried samples are rich in hydroxyl or proton functions. The fraction contained in the exchangeable radicals may be balanced with water containing as few tritium as possible, representing the "exchangeable tritium". The methods applied in this specific case are still experimental.

\section{References}

[1] Belot Y., Roy M., Métivier H., Le Tritium de l'environnement à l'Homme, (IPSN, Les éditions de physique, 1996), p1-191.

[2] IAEA Technical Report Series, Tritium and other environmental isotopes in the hydrological cycle, $n^{\circ} 73$, (IAEA, 1989).

[3] IAEA Technical Report Series, Measurement of radionuclides in food and the environment, $n^{\circ} 295$, (IAEA, 1989).

[4] NF M 60-802-1, 2000, Mesurage de l'activité des émetteurs bêta dans les eaux par scintillation liquide. Partie 1: cas particulier du tritium.

[5] Fournier M., Coreau N., Maigret A., Calmet D., Le mesurage du tritium des échantillons de l'environnement à l'IPSN, Journées techniques CETAMA, Cadarache, (CETAMA,1999). 